\title{
Optimal Adiposity Measurement and Risk Stratification in Established Ischaemic Stroke
}

\author{
Olive Lennon, Catherine Blake \\ School of Public Health, Physiotherapy and Population Science, University College Dublin, Dublin, Ireland \\ Email: olive.lennon@ucd.ie
}

Received 20 September 2014; revised 9 November 2014; accepted 20 November 2014

Copyright (C) 2014 by authors and Scientific Research Publishing Inc.

This work is licensed under the Creative Commons Attribution International License (CC BY). http://creativecommons.org/licenses/by/4.0/

(c) (†) Open Access

\begin{abstract}
Background: Prevention strategies post-stroke should target risk factor reduction which includes consideration of weight, diet and lipoprotein profiles. Limited data informs the optimal adiposity measurement post-stroke to target those at highest recurrent risk. This study aims to identify adiposity measurement/s post-stroke that best predict cardiovascular and co-morbid risk. Subjects and Methods: 142 stroke patients (100 males, 42 females; mean age 63 years) participated. Adiposity and metabolic profiles included BMI, waist circumference, waist to height ratio (WHR), triglyceride levels and hypertriglyceridemic waist. The predictive ability of these measures with indices of cardiovascular risk (Cardiovascular Risk Score) and co-morbidity (Charlson's co-morbidity index) were examined. Results: In hierarchical multiple regression models, age and gender controlled, waist $(p=0.002)$, triglyceride levels $(p=0.006)$, BMI and WHR $(p=0.014)$, uniquely and significantly contributed to the variance in cardiovascular risk, in their models. Only one combination of measures (waist and triglyceride levels) improved the predictive ability of waist in cardiovascular risk stratification $(p=0.001)$. In men, waist $(p=0.013)$ and in women triglyceride levels $(p=0.012)$ performed as the best predictors of cardiovascular risk respectively. No combination of measures was superior to triglyceride levels in women or waist circumference measures in men in predicting cardiovascular risk. With Charlson's co-morbidity index as the dependent variable, triglyceride levels significantly contributed to variance of the model with age and gender influences controlled $(p=0.047)$. No combination of measures improved the predictive ability of triglyceride levels for co-morbidity. Conclusion: Waist circumference and triglyceride levels should form a minimum dataset for adiposity when considering cardiovascular and comorbid risk poststroke.
\end{abstract}

\section{Keywords}

Stroke, Adiposity, Obesity, Abdominal, Measurement, Risk Factors 


\section{Introduction}

Recent improvements in stroke care have significantly improved survival rates [1] [2], resulting in increasing prevalence of those at risk of recurrent vascular events [3]. Patients who survive a stroke or transient ischaemic attack are at particularly high risk for recurrent stroke or subsequent cardiovascular events, including myocardial infarction and death from vascular causes [4]. The 5-year major cardiovascular event rate after an index stroke is estimated to be $24 \%$ [5]. Case fatality rates for recurrent stroke are twice those of first stroke [6] [7] with cardiac disease accounting for as many deaths as recurrent stroke [8]. This highlights the increasing need for disease management and targeted secondary prevention interventions. Obesity is associated with higher cardiovascular event rates including stroke [9]. However, in subjects with established stroke and higher cardiovascular risk, patient specific approaches to assessment and management are required.

In stroke, systemic hypertension and obesity, major cardiovascular risk factors, have an interactive relationship [10]. While body mass index (BMI) is established as an independent risk factor for all cardiovascular disease (CVD), attention has recently been drawn to alternate measures of adiposity that provide information about patterns of body fat distribution [11]. It is recognized that abdominally obese individuals (android obesity) tend to have increased risk of hypertension, dyslipidaemia, CVD and premature death compared with individuals with gynoid or gynecoid obesity (fat distributed in the hip and thigh) [12]. Therefore abdominal obesity should represent a better marker of CVD risk and recurrent events post-stroke [13].

Studies addressing adiposity measures and their association with stroke, to date, yield conflicting results. One study in men found a high BMI was associated with a higher risk for stroke [14]; however in a similar study with women, no significant association was demonstrated [15]. Measures of abdominal obesity including waist circumference, waist-to-height ratio found a significant association with the risk of stroke and a stronger association than BMI alone [16] [17]. Studies have not looked in depth at obesity issues in those with established stroke. In one recent study, visceral adiposity as a percentage of total body adipose tissue demonstrated potential as an epidemiological marker, showing high correlations with established markers of cerebrovascular disease in patients with MRI-proven hyper-acute ischaemic stroke [18]. However MRI or CT imaging techniques required are not recommended by the American Heart Association (AHA) as clinically useful measures due to limitations of cost, availability and technical skill [11]. In another study considering BMI and waist to height ratios post stroke, only extreme waist to height ratios ( $<0.3$ or $>0.8$ ) were an independent predictor of 12 month mortality in a Mexican mestizo population with acute ischaemic stroke [19].

Since the first publication describing the hypertriglyceridemic waist concept [20], studies such as that conducted by Kahn and Valdez (2003), have illustrated advantages of using this simple screening phenotype of enlarged waist combined with elevated triglycerides (EWET) to identify individuals with lipid over-accumulation [21]. In support, recent observations continue to indicate that obesity and lipid-related components together can provide a better indicator of atherogenic trends [22]-[24]. EWET has demonstrated utility as a predictor of cardiovascular disease for up to 12 years when other risk factors are controlled [25] and only the simultaneous presence of elevated waist girth and triglyceride concentrations have shown an association with coronary artery disease (CAD) assessed by angiography [20]. As a measure it warrants consideration in stroke.

Clinical adiposity indices need to be evaluated further to refine risk stratification and better target weight loss interventions in the stroke population. While evidence exists that waist circumference is better at risk stratifying those with stroke than BMI [16], a better understanding of the association between fat distribution and lipoprotein profiles in people with known cerebrovascular disease may help inform the clinical pathway to address metabolic risk factor burden. The aim of this study was 1) to perform and examine measurements of adiposity and metabolic risk in patients with established stroke and 2) to examine the relationship of these measures with indices of cardiovascular risk and co-morbidity.

\section{Materials and Methods}

Data collected in this study form part of the baseline data collection from the cardiac rehabilitation adapted for TIA and stroke (CRAFTS) trial (Current Controlled Trials ISCTRN90272638). Subjects with ischaemic stroke were recruited from an outpatient Stroke Rehabilitation Unit, from 4 community based Volunteer Stroke Scheme support groups and TIA subjects were recruited from a TIA clinic in a tertiary hospital in the greater Dublin area. Information leaflets were distributed to potential subjects fulfilling the inclusion criteria. Subjects contacted the principle researcher to indicate interest in participation. All subjects were over 18 years of age, of either gender 
and medically stable $>3$ months post TIA or minor stroke with consent from their consultant neurologist or $>1$ year post ischaemic stroke with G.P. consent from community services.

\subsection{Ethical Considerations and Confidentiality}

The study was approved by University College Dublin Human Research Ethics Committee (Ref HREC-19-06Blake) and Saint James's Hospital SHJ/Adelaide, Meath and National Children's Hospitals AMNCH Research Ethics Committee (Ref REC: 2008/07/03). All participants were volunteers and informed consent was sought. Participants were given a code on entering the study to ensure anonymity.

\subsection{Anthropometric Measurements}

Subjects wore light clothing and removed footwear during testing. A digital scale was used to measure weight to the nearest $0.1 \mathrm{~kg}$. Height was measured to the nearest $0.1 \mathrm{~cm}$ using an anthropometer. BMI was calculated using the formula $\mathrm{kg} / \mathrm{m}^{2}$. Waist circumference was measured in accordance with the ACSM's guidelines for testing. Subjects standing upright and relaxed with a horizontal measure taken at the greatest anterior extension of the abdomen with a flexible yet inelastic tape [26]. Waist to height ratios (WHtR) were calculated with the above measures of waist $(\mathrm{cm}) /$ height $(\mathrm{cm})$.

\subsection{Fasting Lipids}

Fasting lipids were measured from blood samples obtained by venipuncture following an overnight fast of greater than 12 hours by subjects. Serum was analysed using standard enzymatic techniques for total cholesterol and triglycerides. High density lipoprotein (HDL) cholesterol was determined from plasma, low density lipoprotein (LDL) cholesterol using the Friedewald Equation [27]. Elevated triglyceride levels were defined as $\geq 1.7 \mathrm{mmol} / \mathrm{L}$, validated as a cut-off for the risk of cardiovascular disease [28] (Expert Panel of Detection Evaluation and Treatment of High Blood Cholesterol in Adults, 2001). Participants below this were labelled normal (NTg) and those at or above this level as elevated (ETg). Hyper-Triglyceridemic waist (EWET), a classification determined by combined elevated fasting triglyceride levels $(>1.7 \mathrm{mmol} / \mathrm{L})$ and elevated waist girth $(>88 \mathrm{~cm}$ for women and $>102 \mathrm{~cm}$ in men).

\subsection{Cardiovascular Risk Score}

Cardiovascular Risk Score (CRS) was calculated as the 10 year risk of a fatal cardiovascular event. This is an algorithmic score based on age, resting blood pressure, smoking status, diabetic status, total cholesterol and HDL scores [29].

\subsection{The Charlson Comorbidity Index}

The Charlson comorbidity index (CCI) was calculated for each patient. This index can predict the ten-year mortality risk for patients who may have a range of co-morbid conditions [30].

\subsection{Data Analysis}

Baseline characteristics were summarised using descriptive statistics of mean (sd) and frequency. Independent t-tests and chi squared tests identified gender differences in measures of adiposity and cardiovascular risk and co-morbidity scores. Pearson's and point biserial correlation co-efficients examined the linear relationship between continuous and dichotomous measures of adiposity and cardiovascular and co-morbidity risk scores respectively. Hierarchical regression models were employed to analyse how well individual measures of adiposity predicted cardiovascular and co-morbidity scores when age and gender were controlled. Each adiposity measure was tested in a separate model and its significance established, with F tests, comparing the full model with the adiposity measure to the nested model with only age and gender. The relative contribution of each adiposity measure was explored by means of standardised regression coefficients and the change in $\mathrm{R}^{2}$ attributable to each measure. Combinations of unrelated measures i.e. waist, BMI and triglycerides were further explored to determine if a more optimal model could predict cardiovascular and co-morbid risk with age and sex controlled. Ancillary analysis explored differences between the performance of adiposity results in men and women, in sepa- 
rate hierarchical regression models (controlling for age).

\section{Results}

From a total of 473 invited to participate by letter and following 4 information talks at community stroke support groups, a total of 142 subjects (96 ischaemic stroke; 46 TIA), with a mean age of 63 years, consented to participate. Baseline characteristics are summarised in Table 1. No weight measurement was recorded in two cases (subjects $67 \& 73$ ). Participants were unable to stand on the scales due to balance difficulty and alternate means of measurement were unavailable. Lipoprotein results are missing for three subjects (subjects 15, 36 and 38)

Table 1. Baseline characteristics and obesity profiles of participants.

\begin{tabular}{|c|c|c|c|c|c|}
\hline & \multicolumn{2}{|c|}{$\operatorname{Men}(n=100)$} & \multicolumn{2}{|c|}{ Women $(n=42)$} & \multirow{2}{*}{$p$ value } \\
\hline & Mean & (sd) & Mean & (sd) & \\
\hline Age & 62.94 & 12.9 & 63.38 & 12.8 & 0.852 \\
\hline Waist Girth(cm) & 101.45 & 12.0 & 96.83 & 13.6 & 0.047 \\
\hline Weight (kg) & 83.66 & 13.6 & 71.54 & 14.6 & $<0.001$ \\
\hline Height (cm) & 171.94 & 7.1 & 159.63 & 7.4 & $<0.001$ \\
\hline BMI $\left(\mathrm{kg} / \mathrm{m}^{2}\right)$ & 28.40 & 4.8 & 28.23 & 6.6 & 0.187 \\
\hline Waist (cm)/Height (cm) Ratio & 0.59 & 0.1 & 0.61 & 0.1 & 0.015 \\
\hline Cardiovascular Risk Score (CRS) & 5.54 & 4.8 & 2.90 & 3.2 & 0.002 \\
\hline Charlson Co-Mobidity Index & 2.27 & 1.5 & 1.86 & 1.0 & 0.077 \\
\hline Total Cholesterol (mmol/L) & 3.99 & 1.0 & 4.50 & 0.9 & 0.006 \\
\hline High Density Lipoprotein (mmol/L) & 1.31 & 0.4 & 1.47 & 0.4 & 0.036 \\
\hline Low Density Lipoprotein (mmol/L) & 2.08 & 0.9 & 2.45 & 0.8 & 0.021 \\
\hline \multirow[t]{2}{*}{ Triglyceride (mmol/L) } & 1.37 & 0.8 & 1.40 & 1.2 & 0.829 \\
\hline & $\mathbf{n}$ & (\%) & n & $(\%)$ & \\
\hline Smokers & 13 & $13 \%$ & 10 & $24 \%$ & 0.111 \\
\hline Diabetics & 16 & $16 \%$ & 4 & $10 \%$ & 0.311 \\
\hline BMI Categories & & & & & 0.858 \\
\hline Healthy $\leq 25$ & 27 & $27 \%$ & 13 & $32 \%$ & \\
\hline Over Weight $>25 \leq 30$ & 45 & $45 \%$ & 17 & $41 \%$ & \\
\hline Obese $>30$ & 27 & $27 \%$ & 11 & $27 \%$ & \\
\hline Fasting Triglyceride $\geq 1.7 \mathrm{mmol} / \mathrm{L}$ & 23 & $23 \%$ & 10 & $24 \%$ & 0.846 \\
\hline Statin Use & 86 & $86 \%$ & 38 & $90 \%$ & 0.464 \\
\hline Elevated Waist Girth ${ }^{*}$ & 40 & $40 \%$ & 32 & $76 \%$ & $<0.001$ \\
\hline Elevated Waist/Height (>0.5) & 90 & $90 \%$ & 37 & $88 \%$ & 0.463 \\
\hline Waist/triglyceride Combinations & & & & & 0.002 \\
\hline Normal Waist/Normal Triglycerides & 45 & $45 \%$ & 10 & $24 \%$ & \\
\hline Elevated Waist/Normal Triglycerides & 31 & $31 \%$ & 22 & $52 \%$ & \\
\hline Normal Waist/Elevated Triglycerides & 12 & $12 \%$ & 0 & $0 \%$ & \\
\hline Elevated Waist/Elevated Triglycerides & 12 & $12 \%$ & 10 & $24 \%$ & \\
\hline
\end{tabular}


due to difficulty drawing bloods. Subsequently triglyceride levels, triglyceridemic waist and Cardiovascular Risk indices are missing for these subjects.

Between sex differences in characteristics were tested initially and summarised in Table 1. Men, who are weighted more heavily in the cardiovascular risk algorithmic score, demonstrated an expected higher CRS ( $\mathrm{t}=$ $3.24, p=0.002$ ). No significant difference was noted for the Charlson co-morbidity index. Despite no significant difference between groups in statin prescription ( $85 \%$ in men and $90 \%$ in women), women presented with higher lipoprotein profiles for total cholesterol, HDL and LDL levels $(\mathrm{t}=2.80, p=0.006 ; \mathrm{t}=2.12, p=0.036 ; \mathrm{t}=2.34$, $p=0.021$ respectively). No significant gender difference in triglyceride levels was observed. When measures of adiposity were considered, men presented with higher waist scores $(\mathrm{t}=2.01, p=0.047)$ and higher waist to height ratios $(\mathrm{t}=2.47, p=0.015)$. Despite significant differences in weight and height measures, no gender difference in BMI scores or when categorised into healthy, overweight or obese categories was noted. A significantly higher proportion of women relative to men were noted in the elevated waist girth category (Chi square 13.52, $p<0.001)$ and interestingly, despite no significant gender differences in triglyceride scores observed, when categorised by hypertriglyceridemic waist categories, a significantly higher proportion of women were observed in the elevated waist/elevated triglyceride category and differences were significant (Chi square 14.75, $p=0.002)$.

The relationship between continuous and categorical measures of adiposity (BMI, Waist girth, Waist to height ratio, triglyceride levels and hypertriglyceridemic waist category) and the Cardiovascular Risk Score and Charlson co-morbidity index was explored initially using Pearsons correlation and Point Biserial correlation co-efficients respectively. Results are summarised in Table 2. Using classification by Cohen (1988), coefficient values of $\geq 0.3$ and $\geq 0.5$ were considered to indicate moderate and large strength relationships. Although both cardiovascular and comorbidity risk scores demonstrated moderate relationship to each other ( $r=0.33, p<0.001)$ and waist and triglyceride levels also approached a moderate relationship with each other $(r=0.25 ; p=0.003)$, no measure of adiposity demonstrated a moderate or strong relationship with the risk indices. Of note, waist girth demonstrated the strongest linear relationship in relation to cardiovascular risk $(r=0.26, p=0.002)$.

Cardiovascular risk scores and Charlson co-morbidity index were tested individually with hierarchical multiple regression models to identify how much variance in each index was explained by a measure of adiposity

Table 2. Correlation of adiposity measures with Cardiovascular and Charlson risk scores.

\begin{tabular}{|c|c|c|c|}
\hline Pearson's correlation & & Cardiovascular Risk & Charlson Co-Morbidity Index \\
\hline \multirow{2}{*}{ Cardiovascular Risk } & Pearson's r & ------------ & $0.330^{* *}$ \\
\hline & Significance (2-tailed) & ------------- & $<0.001$ \\
\hline \multirow[t]{2}{*}{ Charlson Co-Morbidity Index } & Pearson's r & $0.330^{* *}$ & ------------- \\
\hline & Significance (2-tailed) & $<0.001$ & ----------- \\
\hline \multirow[t]{2}{*}{ Waist (cm) } & Pearson's r & $0.262^{* *}$ & $0.194^{*}$ \\
\hline & Significance (2-tailed) & 0.002 & 0.021 \\
\hline \multirow[t]{2}{*}{$\mathrm{BMI} \mathbf{k g} / \mathrm{m}^{2}$} & Pearson's r & 0.092 & 0.036 \\
\hline & Significance (2-tailed) & 0.282 & 0.674 \\
\hline \multirow[t]{2}{*}{ Triglyceride $\mathrm{mmol} / \mathrm{L}$} & Pearson's r & $0.018^{*}$ & $0.169^{*}$ \\
\hline & Significance (2-tailed) & 0.033 & 0.047 \\
\hline \multirow[t]{2}{*}{ Waist/Height Ratio } & Pearson's r & 0.143 & 0.064 \\
\hline & Significance (2-tailed) & 0.094 & 0.454 \\
\hline \multicolumn{4}{|l|}{ Point Biserial Correlation } \\
\hline \multirow[t]{2}{*}{ Elevated Waist/Elevated Triglycerides (Yes/No) } & Pearson's r & 0.035 & 0.058 \\
\hline & Significance (2-tailed) & 0.677 & 0.496 \\
\hline
\end{tabular}

${ }^{* *}$ Correlation is significant at the 0.01 level (2-tailed); ${ }^{*}$ Correlation is significant at the 0.05 level (2-tailed). 
when age and gender influences were controlled. The measure of adiposity which significantly contributed to the model, generated the highest $\mathrm{R}^{2}$ change and the largest standardised regression coefficient (beta value), thus making the greatest contribution to the hierarchical model, was considered to be the best predictor of Cardiovascular risk or co-morbidity. Results are summarised in Table 3.

Table 3. Hierarchical multiple regression models.

\begin{tabular}{|c|c|c|c|c|c|c|}
\hline \multirow[b]{2}{*}{$\begin{array}{c}\text { Dependent } \\
\text { Variable }\end{array}$} & \multicolumn{2}{|c|}{ Model 1} & \multicolumn{2}{|l|}{ Model 2} & \multicolumn{2}{|c|}{ Contribution of Adiposity Measure } \\
\hline & $\begin{array}{c}\text { Independent } \\
\text { Variables }\end{array}$ & $\mathbf{R}^{2}$ & $\begin{array}{l}\text { Independent } \\
\text { Variables }\end{array}$ & $\mathbf{R}^{2}$ & $\mathbf{R}^{2}$ Change & $\begin{array}{c}\text { Standardised Coefficient } \\
\text { for Adiposity Measure } \\
\text { (Beta) }^{*}\end{array}$ \\
\hline \multirow[t]{15}{*}{$\begin{array}{l}\text { Cardiovascular } \\
\text { Risk Score }\end{array}$} & Age \& Sex & 0.509 & Waist and Model 1 & 0.541 & 0.032 & 0.182 \\
\hline & & $\mathrm{F}_{(2,137)}=70.94$ & & $\mathrm{~F}_{(3,136)}=53.40$ & $F_{(1,136)}=9.51$ & \\
\hline & & $p<0.001$ & & $p<0.001$ & $p=0.002^{* *}$ & \\
\hline & & 0.519 & BMI and Model 1 & 0.54 & 0.021 & 0.146 \\
\hline & & $\mathrm{F}_{(2,135)}=72.80$ & & $\mathrm{~F}_{(3,134)}=52.43$ & $F_{(1,134)}=6.14$ & \\
\hline & & $p<0.001$ & & $p<0.001$ & $p=0.014^{* *}$ & \\
\hline & & 0.509 & WHR and Model 1 & 0.53 & 0.021 & 0.147 \\
\hline & & $\mathrm{F}_{(2,137)}=70.94$ & & $\mathrm{~F}_{(3,136)}=51.11$ & $F_{(1,136)}=6.14$ & \\
\hline & & $p<0.001$ & & $p<0.001$ & $p=0.014^{* *}$ & \\
\hline & & 0.509 & EWET and Model 1 & 0.52 & 0.011 & 0.107 \\
\hline & & $\mathrm{F}_{(2,137)}=70.94$ & & $F_{(3,136)}=49.08$ & $F_{(1,136)}=3.15$ & \\
\hline & & $p<0.001$ & & $p<0.001$ & $p=0.078$ & \\
\hline & & 0.508 & Triglyceride and Model 1 & 0.535 & 0.027 & 0.164 \\
\hline & & $F_{(2,136)}=70.18$ & & $\mathrm{~F}_{(3,135)}=51.73$ & $\mathrm{~F}_{(1,135)}=7.08$ & \\
\hline & & $p<0.001$ & & $p<0.001$ & $p=0.006^{* *}$ & \\
\hline \multirow{15}{*}{$\begin{array}{l}\text { Charlson } \\
\text { Co-Morbidity } \\
\text { INDEX }\end{array}$} & Age \& Sex & 0.082 & Waist and Model 1 & 0.106 & 0.025 & 0.159 \\
\hline & & $\mathrm{F}_{(2,139)}=6.175$ & & $\mathrm{~F}_{(3,138)}=5.47$ & $\mathrm{~F}_{(1,138)}=3.80$ & \\
\hline & & $p=0.003$ & & $p=0.001$ & $p=0.053$ & \\
\hline & & 0.08 & BMI and Model 1 & 0.083 & 0.003 & 0.054 \\
\hline & & $F_{(2,137)}=5.926$ & & $\mathrm{~F}_{(3,136)}=4.08$ & $\mathrm{~F}_{(1,136)}=0.43$ & \\
\hline & & $p=0.003$ & & $p=0.008$ & $p=0.512$ & \\
\hline & & 0.082 & WHR ratio and Model 1 & 0.102 & 0.020 & 0.143 \\
\hline & & $F_{(2,139)}=7.175$ & & $F_{(3,138)}=5.21$ & $F_{(1,138)}=3.10$ & \\
\hline & & $p=0.003$ & & $p=0.002$ & $p=0.080$ & \\
\hline & & 0.082 & EWET and Model 1 & 0.09 & 0.009 & 0.094 \\
\hline & & $F_{(2,139)}=6.175$ & & $\mathrm{~F}_{(3,138)}=4.56$ & $F_{(1,138)}=1.30$ & \\
\hline & & $p=0.003$ & & $p=0.004$ & $p=0.257$ & \\
\hline & & 0.076 & Triglyceride and Model 1 & 0.083 & 0.027 & 0.163 \\
\hline & & $\mathrm{F}_{(2,136)}=5.59$ & & $F_{(3,135)}=5.15$ & $\mathrm{~F}_{(1,135)}=4.10$ & \\
\hline & & $p=0.005$ & & $p=0.002$ & $p=0.047^{* *}$ & \\
\hline
\end{tabular}

BMI: body mass index; WHR: waist to height ratio; EWET: elevated waist, elevated triglycerides; ${ }^{*}$ This is standardised regression coefficient where the predictors have been standardised to have mean of 0 and variance of $1 ;{ }^{* *}$ Significant contribution to variance in the dependent variable, in addition to age and gender. 
Waist, BMI, waist to height ratios and triglyceride levels were all seen to uniquely contribute to the variance in cardiovascular risk, in their respective models. Age and sex accounted for $51 \%$ of the variance, while waist measures explained an additional $3.2 \%$ of the variance in the cardiovascular risk index $\left(\mathrm{R}^{2}\right.$ change $0.032 ; \mathrm{F}_{(1,136)}$ $=9.51 ; p=0.002)$. Triglyceride levels explained an additional $2.7 \%$ of the variance in cardiovascular risk $\left(\mathrm{F}_{(1,135)}\right.$ $=7.08, p=0.006$ ). BMI and waist height ratios each explained an additional $2.1 \%$ of the variance in their individual models achieving statistical significance at $p=0.014$ levels.

With the Charlson co-morbidity index as the dependent variable, triglyceride levels were observed to significantly contribute to their model. Age and gender accounted for $7.6 \%$ of the variance in the dependent variable and triglyceride levels contributing an additional $2.7 \%$ of the overall variance in the index $\left(\mathrm{R}^{2}\right.$ change $0.027 ; \mathrm{F}_{(1 \text {, }}$ ${ }_{135)}=4.00 ; p=0.047$ ). Waist circumference accounted for an additional $2.5 \%$ variance to the $8.2 \%$ attributed to age and sex in the co-morbidity index. The contribution of waist measurement did not reach statistical significance $\left(\mathrm{R}^{2}\right.$ change $\left.0.025 ; \mathrm{F}_{(1,138)}=3.80 ; p=0.053\right)$.

Ancillary analysis, with models run again for each gender with the influence of age controlled, generated interesting results. In men, waist (3.1\% increase; $p=0.013)$, BMI ( $2.1 \%$ increase; $p=0.042)$, waist to height ratios (2.7\% increase; $p=0.023)$ and triglyceride levels (2.3\% increase; $p=0.037)$ continued to significantly and uniquely contribute to the variance in cardiovascular risk scores. However no measure of adiposity with the exception of triglyceride levels ( $8.5 \%$ increase; $p=0.012$ ) contributed significantly to the variance in the dependent cardiovascular risk index in women.

With co-morbidity as the dependent variable, triglyceride levels in men were the only variable that made a unique additional contribution $(2.3 \%$ increase; $p=0.032)$ to the variance observed when the influence of age was controlled. No measure of adiposity uniquely contributed to the variance in comorbidity index in females when the influence of age was controlled.

Combinations of adiposity items were tested, controlling for age and sex, to see if an optimal data set of adiposity measures for risk determination could be established. One combination improved the predictive ability of waist alone in cardiovascular risk. While waist contributed an additional $3.2 \%$ of the variance observed in cardiovascular risk score with the influence of age and sex controlled $(p=0.002)$, waist and triglyceride levels in combination contributed an additional $4.7 \%$ of the variance in cardiovascular risk score $(p=0.001)$.

When this combined waist and triglyceride model was tested in men and women separately, controlling for the influence of age, it continued to significantly contribute to the variance observed in the cardiovascular risk index. This is summarised in Table 4. However, of note, the model was not superior to triglyceride levels alone in women or waist circumference measures in men. No combination of adiposity measures improved the predictive ability of triglyceride levels for co-morbidity scores, with age and sex influences controlled.

\section{Discussion}

Clinical measures of adiposity, fat distribution and lipoprotein profiles were employed post-stroke to test their utility in targeting those at increased vascular and co-morbid risk. Warranting consideration first, is the feasibility of these measures in routine clinical practice. Weight and height and therefore BMI are the most common anthropometric measures captured clinically [31]. This was not always feasible in the post-stroke population

Table 4. Combination of adiposity measures in hierarchical multiple regression models.

\begin{tabular}{|c|c|c|c|c|c|}
\hline \multirow{2}{*}{$\begin{array}{l}\text { Dependent } \\
\text { Variable }\end{array}$} & \multicolumn{2}{|c|}{ Model 1} & \multicolumn{2}{|c|}{ Model 2} & \multirow{2}{*}{$\begin{array}{c}\text { Contribution of Model } 2 \\
\mathrm{R}^{2} \text { Change }\end{array}$} \\
\hline & Independent Variables & $\mathrm{R}^{2}$ & Independent Variables & $\mathrm{R}^{2}$ & \\
\hline \multicolumn{6}{|c|}{ Cardiovascular Risk Score } \\
\hline All & Age \& Sex & $\begin{array}{c}0.508 \mathrm{~F}_{(2,136)}=70.18 \\
p<0.001\end{array}$ & $\begin{array}{l}\text { Waist and Triglyceride } \\
\text { Levels with Model } 1\end{array}$ & $\begin{array}{c}0.555 \mathrm{~F}_{(4,134)}=41.78 \\
p=0.002\end{array}$ & $\begin{array}{c}0.047 \mathrm{~F}_{(2,134)}=7.09 \\
\boldsymbol{p}=\mathbf{0 . 0 0 1}\end{array}$ \\
\hline Male & Age & $\begin{array}{c}0.494 \mathrm{~F}_{(1,96)}=93.74 \\
p<0.001\end{array}$ & $\begin{array}{l}\text { Waist and Triglyceride } \\
\text { Levels with Model } 1\end{array}$ & $\begin{array}{c}0.537 \mathrm{~F}_{(3,94)}=36.40 \\
p<0.001\end{array}$ & $\begin{array}{c}0.043 \mathrm{~F}_{(1,94)}=4.40 \\
\boldsymbol{p}=\mathbf{0 . 0 1 5}\end{array}$ \\
\hline Female & Age & $\begin{array}{c}0.452 \mathrm{~F}_{(1,39)}=32.21 \\
p<0.001\end{array}$ & $\begin{array}{l}\text { Waist and Triglyceride } \\
\text { Levels with Model } 1\end{array}$ & $\begin{array}{c}0.538 \mathrm{~F}_{(3,37)}=14.36 \\
p<0.001\end{array}$ & $\begin{array}{c}0.086 \mathrm{~F}_{(1,37)}=3.42 \\
\boldsymbol{p}=\mathbf{0 . 0 4 3}^{* *}\end{array}$ \\
\hline
\end{tabular}

\footnotetext{
** Significant contribution to variance in the dependent variable, in addition to age and gender or age.
} 
without specialised equipment, as issues of balance and mobility can limit testing both height and weight. However, waist circumference proved a quick and easy measure, feasible for all participants in this current study and has shown high reliability in testing [32].

Additionally, waist circumference represented the best individual index of adiposity for prediction of cardiovascular risk post-stroke. This concurs with findings from a case controlled study by Winter et al., 2008, identifying superior risk stratification by waist girth and waist to height ratios compared to BMI [16]. However that study failed to look at the contribution of lipoprotein measures to risk stratification. Considering a comparator population of peripheral arterial disease, a systematic review identified waist circumference as the strongest, most consistent predictor of cardiovascular event rates compared with BMI and waist to hip ratios [33]. In addition waist circumference has demonstrated high correlation with abdominal obesity assessed by imaging methods [34] and is associated with increased risk for all adiposity-related morbidity and mortality [35].

Triglyceride levels delivered the next best predictive ability of cardiovascular risk above measures of BMI and waist to height ratios and, of note, was the only index included in this study that demonstrated predictive ability of cardiovascular risk in both men and women when considered separately. Combining waist measures and triglyceride levels in regression analysis demonstrated the highest overall predictive ability of cardiovascular risk, when age and gender were controlled. This combination also made a significant contribution to the vascular risk score in both men and women when genders were considered separately. It was not superior to waist circumference in men or triglyceride levels in women for predicting cardiovascular risk.

Contrary to that initially considered, the potential utility post-stroke of the dichotomous hypertriglyceridemic waist nomenclature (EWET) demonstrated no predictive ability of cardiovascular risk in the regression models employed in this study. Considering both measures as continuous variables appears to be the optimal, minimal criteria for considering cardiovascular risk overall post stroke applicable males and females. When considered within gender, waist girth should be more heavily weighted in males and triglycerides in females.

Triglyceride levels were the only measure that demonstrated predictive ability of co-morbidity. Again this measure performed differently across the genders when considered in separate models. No measure of adiposity contributed to the variance observed in co-morbidity models in women alone. Triglyceride levels significantly contribute to the variance in co-morbidity scores in men. No combination of triglyceride levels and unrelated adiposity measure including waist circumference improved the predictive ability of this measure.

BMI and Waist to height ratio (WHtR) did demonstrate a weaker predictive ability of cardiovascular risk, when the influence of age and sex were controlled. These remained significant contributions to the variance in cardiovascular risk in men only but failed to perform as a predictive index in women. A study of 12 month mortality risk following acute ischaemic stroke demonstrated no predictive ability of BMI tested either as continuous or stratified variable. However a U-shaped relationship was observed in the study between baseline waist to height ratio and mortality. On multivariate analysis, baseline WHtR $\leq 0.300$ or $>0.800$ independently predicted all-cause mortality (hazard ratio 1.91, 95\% confidence interval 1.04 - 3.51) [19]. WHtRs in this study were considered a continuous variable and extremes of this measure were not tested. Interestingly a Japanese study noted that WHtR was useful in identifying specific age brackets of middle-aged men and women aged 50 - 69 years of age at higher risk of CVD and was a better predictor than waist circumference of cardiovascular disease, especially in men [36]. This finding was not upheld in this current study, although the specific age bracket (50 - 69 years) was not considered in isolation due to limited sample sizes available.

A higher proportion of women than men, reaching statistical significance in comparison across genders, presented in the EWET category despite no gender difference in triglyceride levels. This variable has recently been shown to have a higher association with diabetes in people with normal BMI [37] and the findings in this study may point towards a stronger cardiometabolic aetiology of stroke in women [38]. A prospective study over 8.5 years of more than 550 women indicated that survival rates dropped significantly in women with an elevated waist girth and high triglyceride concentrations compared to women without these conditions. Moreover, relative risk for all-cause mortality (hazard ratio: 2.2, 95\% CI: 1.3 - 3.6, $p<0.01$ ) and cardiovascular death (hazard ratio: 4.7, 95\% CI: $2.2-9.8, p<0.001$ ) associated with hypertriglyceridemic waist was significant even after adjusting for age, smoking, LDL cholesterol and diabetes [24].

Baseline lipid profiles, which were significantly different between men and women for total cholesterol and LDL cholesterol, suggest less stringent secondary control post-stroke in women. This is borne out in emergent trends in US risk factor control post-stroke. A recent report indicates that despite improvement in cholesterol treatment rates by $10 \%$ and $8 \%$ in men and women respectively, no improvement in control rates was observed 
in women [39]. Sub-optimal control of cholesterol in women may have detrimental consequences, as a recent prospective study has shown poor total, HDL and LDL cholesterol results significantly increases the risk of ischaemic stroke in women only [40].

It is clear from the literature that no one ideal measure of adiposity exists. There is growing evidence that the predictive ability of the measures vary for example between genders, age categories and extremes of the measure [14] [15] [19] [36]. Future prospective studies are required to track the predictive ability of measures of obesity on mortality and cardiovascular event rates post-stroke in men and women of different age categories. This study suggests that waist circumference and triglyceride levels warrant inclusion as a minimum data set of obesity and fat deposition post-stroke and cautions against its use as a dichotomous measure. In addition stroke survivors with an increased waist circumference measure and/or elevated triglyceride levels should receive lifestyle counselling including diet and exercise to reduce their future risk profile.

It is important that equivalent anthropometric measures are utilised [33] across future studies post-stroke to facilitate comparison and meta-analysis.

\section{Study Limitations}

The CRS algorithm employed in this study underestimates risk in those with known cardiovascular disease, however the true value was not of interest here, rather that of a continuous variable that could identify risk. This score is not validated for non-caucasians $(n=2)$ and those over 74 years old $(n=25)$. Analysis, rerun with data from these subjects removed, found no reportable difference in results. Limited numbers of participants were categorised as obese by the BMI $(\mathrm{n}=38)$, however adiposity distribution as distinct from BMI derived categories warrants consideration. Finally, regression analysis in women $(n=42)$ may have limited statistical power and results should be interpreted with a degree of caution (Stevens (1996) recommends a minimum of 15 subjects per predictor in regression analysis [41]).

\section{Conclusion}

Waist circumference represented the single best adiposity predictor post stroke of cardiovascular risk as measured by the CRS. It was simple and easy to measure in the clinical setting and superior to weight derived indices. Waist circumference and triglyceride levels combined provided the best overall predictive ability of vascular risk and should form a minimum data set for adiposity to guide future risk reduction strategies. Triglyceride levels provided the single best adiposity predictor of co-morbidity in the post-stroke population and again warrant inclusion in a minimum data set on these grounds. Prospective studies are required to identify optimum gender and age related indices of future risk as results from this study, supported by the literature, suggest measures of adiposity may not generalise well across these categories.

\section{Acknowledgements}

This study received a Health Research Board Ireland Award HSR/2007/06 and University College Dublin Seed Funding SF109.

\section{Conflict of Interest Statement}

The authors declare no financial interests or other conflict of interest in relation to the work submitted.

\section{References}

[1] Langhorne, P., Williams, B., Gilchrist, W. and Howie, K. (1993) Do Stroke Units Save Lives? The Lancet, 342, 395398. http://dx.doi.org/10.1016/0140-6736(93)92813-9

[2] Albers, G.W. (2010) Stroke: More Protection for Patients with Atrial Fibrillation. The Lancet Neurology, 9, 2-4. http://dx.doi.org/10.1016/S1474-4422(09)70306-0

[3] Bennett, K., Kabir, Z., Unal, B., Shelley, E., Critchley, J., Perry, I., et al. (2006) Explaining the Recent Decrease in Coronary Heart Disease Mortality Rates in Ireland, 1985-2000. Journal of Epidemiology and Community Health, 60, 322-327. http://dx.doi.org/10.1136/jech.2005.038638

[4] Touze, E., Coste, J., Voicu, M., Kansao, J., Masmoudi, R., Doumenc, B., et al. (2008) Importance of In-Hospital Initia- 
tion of Therapies and Therapeutic Inertia in Secondary Stroke Prevention-IMplementation of Prevention after a Cerebro-Vascular evenT (IMPACT) Study. Stroke, 39, 1834-1843.

http://dx.doi.org/10.1161/STROKEAHA.107.503094

[5] Hackam, D.G. and Spence, J.D. (2007) Combining Multiple Approaches for the Secondary Prevention of Vascular Events after Stroke: A Quantitative Modeling Study. Stroke, 38, 1881-1885. http://dx.doi.org/10.1161/STROKEAHA.106.475525

[6] Sacco, R., Shi, T., Zamanillo, M. and Kargman, D. (1994) Predictors of Mortality and Recurrence after Hospitalized Cerebral In-Farction in an Urban Community: The Northern Manhattan Stroke Study. Neurology, 44, 626-34. http://dx.doi.org/10.1212/WNL.44.4.626

[7] Hankey, G., Jamrozik, K., Broadhurst, R., Forbes, S., Burvill, P.W., Anderson, C.S., et al. (1998) Long-Term Risk of First Recurrent Stroke in the Perth Community Stroke Study. Stroke, 29, 2491-500. http://dx.doi.org/10.1161/01.STR.29.12.2491

[8] Petty, G., Brown Jr., R., Whisnant, J., Sicks, J., O’Fallon, W. and Wiebers, D. (1998) Survival and Recurrence after First Cerebral In-Farction: A Population-Based Study in Rochester, Minnesota, 1975 through 1989. Neurology, 50, 208. http://dx.doi.org/10.1212/WNL.50.1.208

[9] Suk, S.-H., Sacco, R.L., Boden-Albala, B., Cheun, J.F., Pittman, J.G., Elkind, M.S., et al. (2003) Abdominal Obesity and Risk of Is-Chemic Stroke the Northern Manhattan Stroke Study. Stroke, 34, 1586-1592. http://dx.doi.org/10.1161/01.STR.0000075294.98582.2F

[10] Chrostowska, M., Szyndler, A., Hoffmann, M. and Narkiewicz, K. (2013) Impact of Obesity on Cardiovascular Health. Best Practice \& Research Clinical Endocrinology \& Metabolism, 27, 147-56. http://dx.doi.org/10.1016/j.beem.2013.01.004

[11] Cornier, M.-A., Despres, J.-P., Davis, N., Grossniklaus, D.A., Klein, S., Lamarche, B., et al. (2011) Assessing Adiposity: A Scientific Statement from the American Heart Association. Circulation, 124, 1996-2019. http://dx.doi.org/10.1161/CIR.0b013e318233bc6a

[12] Folsom, A.R., Kaye, S.A., Sellers, T.A., Hong, C.P., Cerhan, J.R., Potter, J.D., et al. (1993) Body Fat Distribution and 5-Year Risk of Death in Older Women. JAMA: The Journal of the American Medical Association, 269, $483-487$. http://dx.doi.org/10.1001/jama.269.4.483 http://dx.doi.org/10.1001/jama.1993.03500040049035

[13] Rheaume, C., Leblanc, M.-E. and Poirier, P. (2011) Adiposity Assessment: Explaining the Association between Obesity, Hypertension and Stroke. Expert Review of Cardiovascular Therapy, 9, 1557-1564. http://dx.doi.org/10.1586/erc.11.167

[14] Kurth, T., Gaziano, J.M., Berger, K., Kase, C.S., Rexrode, K.M., Cook, N.R., et al. (2002) Body Mass Index and the Risk of Stroke in Men. Archives of Internal Medicine, 162, 2557. http://dx.doi.org/10.1001/archinte.162.22.2557

[15] Lu, M., Ye, W., Adami, H. and Weiderpass, E. (2006) Prospective Study of Body Size and Risk for Stroke amongst Women below Age 60. Journal of Internal Medicine, 260, 442-450. http://dx.doi.org/10.1111/j.1365-2796.2006.01706.x

[16] Winter, Y., Rohrmann, S., Linseisen, J., Lanczik, O., Ringleb, P.A., Hebebrand, J., et al. (2008) Contribution of Obesity and Abdominal Fat Mass to Risk of Stroke and Transient Ischemic Attacks. Stroke, 39, 3145-3151. http://dx.doi.org/10.1161/STROKEAHA.108.523001

[17] Cheal, K., Abbasi, F., Lamendola, C., McLaughlin, T., Reaven, G. and Ford, E.D. (2004) Relationship to Insulin Resistance of the Adult Treatment Panel III Diagnostic Criteria for Identification of the Metabolic Syndrome. Diabetes and Vascular Disease Research, 53, 1195-1200.

[18] Karcher, H.-S., Holzwarth, R., Mueller, H., Ludolph, A.C., Huber, R., Kassubek, J., et al. (2013) Body Fat Distribution as a Risk Factor for Cerebrovascular Disease: An MRI-Based Body Fat Quantification Study. Cerebrovascular Diseases, 35, 341-348. http://dx.doi.org/10.1159/000348703

[19] Chiquete, E., Ruiz-Sandoval, J.L., Murillo-Bonilla, L., León-Jiménez, C., Ruiz-Madrigal, B., Martínez-López, E., et al. (2013) Central Adiposity and Mortality after First-Ever Acute Ischemic Stroke. European Neurology, 70, 117-123. http://dx.doi.org/10.1159/000350762

[20] Lemieux, I., Pascot, A. and Couillard, C. (2000) Hypertriglyceridemic Waist: A Marker of the Atherogenic Metabolic Triad (Hyperinsulinemia; Hyperapolipoprotein B; Small, Dense LDL) in Men? Circulation, 102, 179-184. http://dx.doi.org/10.1161/01.CIR.102.2.179

[21] Kahn, H. and Valdez, R. (2003) Metabolic Risks Identified by the Combination of Enlarged Waist and Elevated Triacylglycerol Concentration. The American Journal of Clinical Nutrition, 78, 928-934.

[22] Raji, A. and Plutzky, J. (2002) Insulin Resistance, Diabetes, and Atherosclerosis: Thiazolidinediones as Therapeutic Interventions. Current Cardiology Reports, 4, 514-521. http://dx.doi.org/10.1007/s11886-002-0116-3 
[23] Hanley, A.J., Williams, K., Stern, M.P. and Haffner, S.M. (2002) Homeostasis Model Assessment of Insulin Resistance in Relation to the Incidence of Cardiovascular Disease: The San Antonio Heart Study. Diabetes Care, 25, 11771184. http://dx.doi.org/10.2337/diacare.25.7.1177

[24] Tanko, L.B., Bagger, Y.Z., Alexandersen, P., Larsen, P.J. and Christiansen, C. (2003) Peripheral Adiposity Exhibits an Independent Dominant Antiatherogenic Effect in Elderly Women. Circulation, 107, 1626-1631. http://dx.doi.org/10.1161/01.CIR.0000057974.74060.68

[25] Fisher, M. (2006) Cardiometabolic Disease: The New Challenge? Practical Diabetes International, 23, 95-97. http://dx.doi.org/10.1002/pdi.909

[26] Thompson, W.R., Gordon, N.F. and Pescatello, L.S., American College of Sports Medicine, et al. (2010) ACSM's Guidelines for Exercise Testing and Prescription: 2010. Lippincott Williams \& Wilkins, Philadelphia.

[27] Friedewald, W., Levy, R. and Frederickson, D. (1972) Estimation of VLDL- and LDL-Cholesterol. Clinical Chemistry, 18, 499-502.

[28] National Institutes of Health (2001) Third Report of the National Cholesterol Education Program Expert Panel on Detection, Evaluation, and Treatment of High Blood Cholesterol in Adults (Adult Treatment Panel III). NIH Publication No. 01-3670.

[29] Wilson, P., D’Agostino, R., Levy, D., Belanger, A., Silbershatz, H. and Kannel, W. (1998) Prediction of Coronary Heart Disease Using Risk Factor Categories. Circulation, 97, 1837-1847. http://dx.doi.org/10.1161/01.CIR.97.18.1837

[30] Charlson, M.E., Pompei, P., Ales, K.L. and MacKenzie, C.R. (1987) A New Method of Classifying Prognostic Comorbidity in Longitudinal Studies: Development and Validation. Journal of Chronic Diseases, 40, 373-383. http://dx.doi.org/10.1016/0021-9681(87)90171-8

[31] Franzosi, M.G. (2006) Should We Continue to Use BMI as a Cardiovascular Risk Factor? The Lancet, 368, $624-625$. http://dx.doi.org/10.1016/S0140-6736(06)69222-2

[32] Chen, M.M., Lear, S.A., Gao, M., Frohlich, J.J. and Birmingham, C.L. (2001) Intraobserver and Interobserver Reliability of Waist Circumference and the Waist to Hip Ratio. Obesity Research, 9, 651-651. http://dx.doi.org/10.1038/oby.2001.87

[33] Cronin, O., Morris, D., Walker, P. and Golledge, J. (2013) The Association of Obesity with Cardiovascular Events in Patients with Peripheral Artery Disease. Atherosclerosis, 228, 316-323. http://dx.doi.org/10.1016/j.atherosclerosis.2013.03.002

[34] Pouliot, M.-C., Despres, J.-P., Lemieux, S., Moorjani, S., Bouchard, C., Tremblay, A., et al. (1994) Waist Circumference and Abdominal Sagittal Diameter: Best Simple Anthropometric Indexes of Abdominal Visceral Adipose Tissue Accumulation and Related Cardiovascular Risk in Men and Women. The American Journal of Cardiology, 73, 460468. http://dx.doi.org/10.1016/0002-9149(94)90676-9

[35] de Koning, L., Merchant, A.T., Pogue, J. and Anand, S.S. (2007) Waist Circumference and Waist-to-Hip Ratio as Predictors of Cardiovascular Events: Meta Regression Analysis of Prospective Studies. European Heart Journal, 28, 850856. http://dx.doi.org/10.1093/eurheartj/ehm026

[36] Tatsumi, Y., Watanabe, M., Kokubo, Y., Nishimura, K., Higashiyama, A., Okamura, T., et al. (2013) Effect of Age on the Association between Waist-to-Height Ratio and Incidence of Cardiovascular Disease: The Suita Study. Journal of Epidemiology, 23, 351-359.

[37] Daniel, M., Paquet, C., Kelly, S., Zang, G., Rowley, K.G., McDermott, R., et al. (2013) Hypertriglyceridemic Waist and Newly-Diagnosed Diabetes among Remote-Dwelling Indigenous Australians. Annals of Human Biology, 40, 496504. http://dx.doi.org/10.3109/03014460.2013.806588

[38] Chen, H.-J., Bai, C.-H., Yeh, W.-T., Chiu, H.-C. and Pan, W.-H. (2006) Influence of Metabolic Syndrome and General Obesity on the Risk of Ischemic Stroke. Stroke, 37, 1060-1064. http://dx.doi.org/10.1161/01.STR.0000206458.58142.f3

[39] Shah, N., Huffman, M., Ning, H. and Lloyd-Jones, D. (2013) Trends in Vascular Risk Factor Treatment and Control in US Stroke Survivors. The National Health and Nutrition Examination Surveys (1999-2010). Circulation: Cardiovascular Quality and Outcomes, 6, 270-277. http://dx.doi.org/10.1161/CIRCOUTCOMES.113.000112

[40] Tohidi, M., Mohebi, R., Cheraghi, L., Hajsheikholeslami, F., Aref, S., Nouri, S., et al. (2013) Lipid Profile Components and Incident Cerebrovascular Events versus Coronary Heart Disease; The Result of 9 Years Follow-Up in Tehran Lipid and Glucose Study. Clinical Biochemistry, 46, 716-721. http://dx.doi.org/10.1016/j.clinbiochem.2013.03.012

[41] Steevens, J. (1996) Applied Multivariate Statistics for the Social Sciences. 3rd Edition, Lawrence Erblaum Associates, Mahwah, New Jersey. 
Scientific Research Publishing (SCIRP) is one of the largest Open Access journal publishers. It is currently publishing more than 200 open access, online, peer-reviewed journals covering a wide range of academic disciplines. SCIRP serves the worldwide academic communities and contributes to the progress and application of science with its publication.

Other selected journals from SCIRP are listed as below. Submit your manuscript to us via either submit@scirp.org or Online Submission Portal.
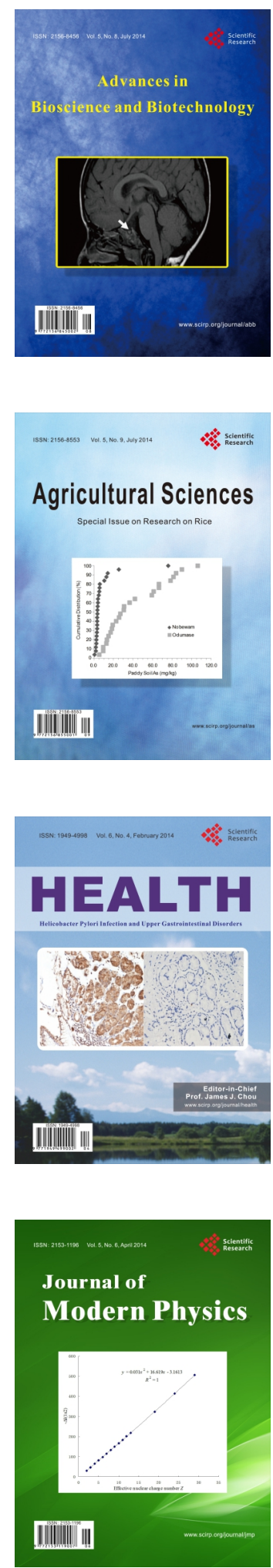
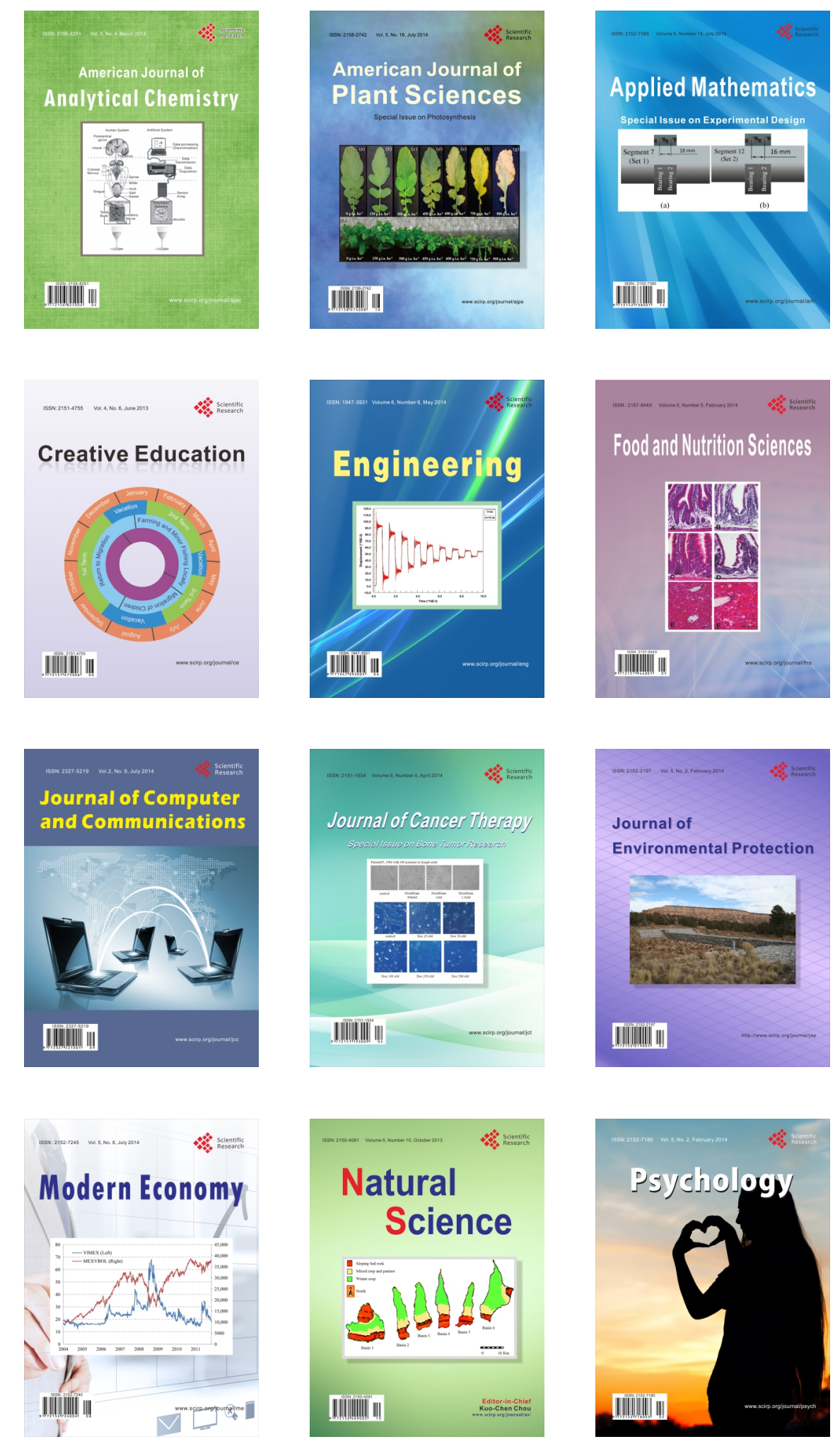